INVESTIGACIÓN

http://doi.org/10.15198/seeci.2019.49.81-102

Recibido: 14/12/2018 --- Aceptado: 22/02/2019 --- Publicado: 15/07/2019

\title{
LA MUJER EN EL PODER LEGISLATIVO DE ECUADOR: ANÁLISIS DESDE LA COMUNICACIÓN VERBAL Y NO VERBAL
}

\section{WOMEN IN THE LEGISLATIVE POWER OF ECUADOR: ANALYSIS FROM VERBAL AND NON-VERBAL COMMUNICATION}

\author{
(iD) 8 Geoconda Pila Cárdenas ${ }^{\mathbf{1}}$ : Universidad Complutense de Madrid. \\ España. \\ gpila@ucm.es
}

\section{RESUMEN}

En este artículo analizamos la comunicación verbal y no verbal de los discursos pronunciados durante la toma de posesión del cargo de las tres primeras autoridades del poder legislativo de Ecuador del período comprendido entre mayo de 2013 y el mismo mes de 2017. El 14 de mayo de 2013 Gabriela Rivadeneira fue elegida presidenta de la Asamblea Nacional; Rosana Alvarado, primera vicepresidenta; y Marcela Aguiñaga, segunda vicepresidenta. Esta elección parlamentaria tiene especial relevancia, pues, por primera vez en la historia del país, una mujer fue elegida primera autoridad del legislativo. En segundo lugar, con 29 años, Rivadeneira se convirtió en la presidenta más joven de un Parlamento en América. En tercer lugar, es la primera legislatura en la que el 39\% de asambleístas son mujeres; y cuarto, es la primera ocasión en que tres mujeres alcanzan los espacios de poder más altos en esta entidad del Estado. El análisis de la banda verbal describe cuál es la finalidad principal de cada discurso y los materiales de credibilidad, de argumento y dramáticos que las oradoras emplean. En la banda no verbal observamos qué uso hacen las legisladoras del paralenguaje y el lenguaje corporal; y qué manifestaciones de afecto transmiten. Estos tres discursos representan un hito significativo en los logros de la mujer en la política ecuatoriana y muestran claramente los estilos de comunicar que cada una de estas asambleístas mantuvo a lo largo de su legislatura.

PALABRAS CLAVE: discurso político - comunicación no verbal - análisis de discurso - política ecuatoriana - mujer en la política - comunicación verbal - poder legislativo.

\footnotetext{
${ }^{1}$ Geoconda Pila Cárdenas: cursa el Doctorado en Comunicación Audiovisual, Publicidad y Relaciones Públicas de la Universidad Complutense de Madrid. Se ha desempeñado como asesora de comunicación de las Comisiones de Justicia y Biodiversidad de la Asamblea Nacional del Ecuador. gpila@ucm.es
} 
Pila Cárdenas, G. La mujer en el poder legislativo de Ecuador: análisis desde la comunicación verbal y no verbal

\section{ABSTRACT}

In this article we analyze the verbal and non-verbal communication of the speeches made during the inauguration of the three main authorities of the legislative power of Ecuador from May 2013 to May 2017. On May 14, 2013 Gabriela Rivadeneira was elected president of the Asamblea Nacional del Ecuador; Rosana Alvarado, first vice president; and Marcela Aguiñaga, second vice president. This parliamentary election has special relevance, because, for the first time in the history of the country, a woman was chosen like first authority of the legislative. Second, at age 29, Rivadeneira became the youngest president of a Parliament in America. Third, it is the first legislature in which $39 \%$ of assembly members are women; and fourth, is the first time that three women reach the highest power spaces in this state entity. The verbal analysis describes the main purpose of each discourse and the credible, argumentative and dramatic materials that the speakers use. Regarding the nonverbal band, we observe how the legislators use paralanguage and body language; and what manifestations of affection they transmit. These three speeches represent a significant moment in the achievements of women in Ecuadorian politics and clearly show the styles of communication that each of these assembly members maintained throughout their legislature.

KEY WORDS: political speech - nonverbal communication - discourse analysis ecuadorian politics - women in politics - verbal communication - legislative power.

\section{A MULHER NO PODER LEGISLATIVO DO EQUADOR: ANALISES DESDE A COMUNICAÇÃO VERBAL E NÃO VERBAL}

\section{RESUME}

Neste artigo analisamos a comunicação verbal e não verbal dos discursos pronunciados durante a toma de possessão do cargo das 3 primeiras autoridades do poder legislativo do Equador do período compreendido entre maio de 2013 e maio de 2017. No dia 14 de maio de 2013 Gabriela Rivadeneira foi eleita presidente da Assembleia Nacional, Rosana Alvarado, primeira vice-presidente; e Marcela Aguiñaga, segunda vice-presidente. Esta eleição parlamentaria tem especial relevância pois, pela primeira vez na história do País, uma mulher foi eleita a primeira autoridade do legislativo. Em segundo lugar, com 29 anos, Rivadeneira converteu-se em a presidente mais jovem do parlamento na América. Em terceiro lugar, é a primeira legislatura na qual $39 \%$ da assembleia são mulheres; e em quarto, é a primeira ocasião em que 3 mulheres alcançam os espaços de poder mais altos nesta entidade do Estado. A analises da parte verbal descreve qual é a finalidade principal de cada discurso e os materiais de credibilidade, de argumentos dramáticos que as oradoras empregam. Na parte não verbal observamos que uso fazem as legisladoras da paralinguagem e linguagem corporal; e que manifestações de afeto transmitem. Estes três discursos representam um marco significativo nas conquistas da mulher na política equatoriana e mostram claramente os estilos de comunicar que cada uma dessas mantivera ao largo de sua legislatura. 
Pila Cárdenas, G. La mujer en el poder legislativo de Ecuador: análisis desde la comunicación verbal y no verbal

PALAVRAS CHAVE: discurso político - comunicação não verbal - analises de discurso - política equatoriana - mulher na política - comunicação verbal - poder legislativo.

\section{Cómo citar el artículo:}

Pila Cárdenas, G. (2019). La mujer en el poder legislativo de Ecuador: análisis desde la comunicación verbal y no verbal. [Women in the legislative power of Ecuador: analysis from verbal and non-verbal communication]. Revista de Comunicación de la SEECI, 49, 81-102. doi: http://doi.org/10.15198/seeci.2019.49.81-102

Recuperado de http://www.seeci.net/revista/index.php/seeci/article/view/565

\section{INTRODUCCIÓN}

Ecuador es un país que sufrió importantes cambios estructurales e institucionales a partir de la aprobación de la Constitución de 2008. Uno de ellos se originó en los artículos 65, 70 y 116 de la Carta Magna que obligan al Estado ecuatoriano a promover la representación paritaria de mujeres y hombres en los cargos de nominación o designación de la función pública y adoptar medidas de acción afirmativa que permitan garantizar la participación de sectores históricamente discriminados (Asamblea Constituyente del Ecuador, 2008, pp. 4976).

En ese contexto, el período legislativo 2013-2017 marcó un hito en el país, en términos de participación política de la mujer, por varias razones. En primer lugar, porque por primera vez una mujer fue elegida presidenta de la Función Legislativa. En segundo, porque Gabriela Rivadeneira, con solo 29 años se convirtió en la persona más joven de América Latina en dirigir un parlamento (Agencia EFE, 2013). Por otra parte, tres mujeres fueron simultáneamente elegidas presidenta, primera y segunda vicepresidenta de la Asamblea Nacional (Jácome, 2013), algo que nunca había ocurrido; $y$, finalmente, fue la primera legislatura en que las mujeres alcanzaron el $39 \%$ de escaños, es decir, casi la paridad total (Cisneros-Palacios, 2013, p. 4).

Este cambio constitucional responde una necesidad de representatividad de la mujer en la política, pues antes de este período, en promedio, apenas el $5 \%$ de mujeres ocupaban una curul en Ecuador. Para ello, se creó la obligación de que las listas de candidatos, presentadas por los partidos y organizaciones políticas, deben aparecer en secuencia de mujer - hombre u hombre - mujer hasta alcanzar la totalidad de candidaturas (Asamblea Nacional del Ecuador, 2009b, p. 28).

El 14 de mayo de 2013, Gabriela Rivadeneira fue elegida presidenta de la Asamblea Nacional del Ecuador, Rosana Alvarado, primera vicepresidenta y Marcela Aguiñaga, segunda vicepresidenta. En el momento de su elección, las tres legisladoras pertenecían al Movimiento Alianza PAIS que en ese período alcanzó 100 de 137 curules (Consejo Nacional Electoral, 2013, p. 94). 
Puesto que este artículo busca enfatizar la importancia de la participación de la mujer en la política en América Latina, hemos revisado los aportes de María Teresa Piñeiro (2003), Natalia D'Elia (2013), María Teresa Bejarano (2013) e Inmaculada Espizua y Graciela Padilla (2017) quienes se cuestionan, por ejemplo, si las políticas de paridad equivalen a igualdad o si el uso de lenguaje no sexista tiene un carácter performativo en cuestiones de género. Además, analizan la imagen de la mujer política española como elemento de su comunicación y las representaciones femeninas en la publicidad.

Para el análisis verbal de los discursos de toma de posesión de Rivadeneira (2013), Alvarado (2013) y Aguiñaga (2013) empleamos los elementos de la Retórica de Aristóteles (1990), además, de estudiosos contemporáneos del tema como Felicísimo Valbuena de la Fuente (1997 y 2014), Paula Requeijo (2010), Inmaculada Berlanga, Francisco García y Juan Victoria (2013), Graciela Padilla (2014 y 2015) y Aurora García, Sarai Lagos y María Lourdes Román (2018). En este apartado identificaremos el tipo de discurso que cada una pronuncia, su finalidad y qué materiales de credibilidad, argumento y dramáticos muestran.

En lo que respecta al análisis no verbal nos centraremos en los distintos elementos del paralenguaje, kinésica y artefactos, empleando las categorías aportadas por autores como Paul Ekman y Wallace Friesen (1969), Desmond Morris (1980), Mark Knapp (1992), Fernando Poyatos (1994), Julius Fast (1999), Flora Davis (2005), y los ya citados académicos Valbuena, Padilla y Requeijo. María Elena del Valle (2008) y Jonathan Rodríguez (2018) complementan estos aportes con una mirada sobre la indumentaria como símbolo cultural y el vestuario como elemento de análisis en la comunicación no verbal.

\section{OBJETIVOS}

\subsection{General}

Realizar un análisis desde la retórica y el lenguaje no verbal de los discursos de posesión de presidenta y primera y segunda vicepresidenta de Gabriela Rivadeneira, Rosana Alvarado y Marcela Aguiñaga.

\subsection{Específicos}

1. Determinar cuál es el tipo de discurso empleado por las legisladoras y qué materiales de credibilidad, argumento y dramáticos muestran.

2. Analizar cuál es el empleo del paralenguaje que hacen estas políticas y explicar cómo el lugar geográfico de origen de estas tres mujeres influye en este aspecto.

3. Analizar el lenguaje corporal que exhiben las asambleístas mientras pronuncian sus discursos de toma de posesión, especialmente, manifestaciones de afecto, emblemas, ilustradores y adaptadores. 
Pila Cárdenas, G. La mujer en el poder legislativo de Ecuador: análisis desde la comunicación verbal y no verbal

\section{METODOLOGÍA}

Según datos oficiales del Consejo Nacional Electoral del Ecuador (2013, pp. 17 y 257), de 137 asambleístas elegidos para el período legislativo 2013 - 2017, 53 son mujeres. El primer desafío de este trabajo fue determinar cuáles de estas 53 mujeres serían objeto de análisis y por qué. Para ello tomamos en cuenta varios factores como trabajo legislativo, visibilidad mediática, aceptación de la gestión por parte de los ciudadanos y popularidad en redes sociales.

Estos elementos, sumados a los hitos antes mencionados, nos llevaron a la conclusión de que las representantes idóneas para este estudio son precisamente las más altas autoridades de la Asamblea Nacional. Decidimos que los discursos que mejor se adaptan a las necesidades de esta primera aproximación son los de toma de posesión porque son los únicos que versan sobre un tema común y han sido pronunciados por las tres en una misma sesión. Posteriormente, determinamos las categorías de análisis que emplearemos para este estudio, las cuales explicamos a continuación:

\subsection{Banda verbal}

\subsubsection{Tipos de discursos}

Aristóteles en su obra Retórica, señala que el discurso consta de tres componentes: el que habla (orador), aquello de lo que habla (mensaje) y aquel a quien habla (oyente). A partir de este último, establece tres géneros de discursos: deliberativo, judicial y epidíctico o demostrativo.

Tres son en número las especies de la retórica, dado que otras tantas son las clases de oyentes de discursos que existen. Porque el discurso consta de tres componentes: el que habla, aquello de lo que habla y aquél (sic) a quien habla; pero el fin se refiere a este último, quiero decir, al oyente (...). De modo que es preciso que existan tres géneros de discursos retóricos: el deliberativo, el judicial y el epidíctico. (Aristóteles, 1990, pp. 193 - 194)

En cuanto a las características que nos permiten identificar cada uno, Aristóteles (1990, pp. 194-195) explica que lo propio del discurso deliberativo es "el consenso y la disuasión", siendo su tiempo "el futuro" y su finalidad "lo conveniente y lo perjudicial". En el discurso judicial, lo propio "es la acusación o la defensa". Su tiempo es "el pasado", mientras que su finalidad es lo "justo y lo injusto". Finalmente, el discurso demostrativo se caracteriza por recurrir "al elogio o la censura". Su tiempo más apropiado "es el presente" y la finalidad que se persigue es "lo bello y lo vergonzoso".

\subsubsection{Propósito del discurso}

En cuanto al "para qué habla el orador" o propósito del discurso, el catedrático Felicísimo Valbuena de la Fuente señala que existen nueve finalidades: informar, 
Pila Cárdenas, G. La mujer en el poder legislativo de Ecuador: análisis desde la comunicación verbal y no verbal

exponer, influir en una audiencia, convencer, inspirar o motivar, estimular, conseguir una acción, persuadir, y, alabar o vituperar (Valbuena, 1997, pp. 521-558).

\subsubsection{Materiales retóricos}

Como apartado final de la banda verbal de los discursos seleccionados analizaremos los materiales retóricos. Aristóteles propone tres especies de pruebas por persuasión:

De entre las pruebas por persuasión, las que pueden obtenerse mediante el discurso son de tres especies: unas residen en el talante del que habla, otras en predisponer al oyente de alguna manera $y$, las últimas, en el discurso mismo, merced a lo que este demuestra o parece demostrar (1990, p. 175).

Estas "especies de pruebas por persuasión" son conocidas (y así constará en referencias posteriores) como: materiales de credibilidad o ethos, materiales de argumento o logos, y materiales dramáticos o pathos.

Aristóteles señala que, por su origen, hay pruebas inartísticas o "ajenas al arte", lo que significa que "que existían de antemano"; y otras artísticas o que son "propias del arte", lo que supone "que pueden prepararse con método y por nosotros mismos" (1990, p. 174).

\subsection{Banda no verbal}

Mark L. Knapp (1992, p. 41) explica que "Comúnmente se utiliza el término no verbal para describir todos los acontecimientos de la comunicación humana que trascienden las palabras dichas o escritas". Es tal su importancia en el marco de la comunicación entendida como un fenómeno integral, que Ray Birdwhistell afirma que: "no más del 35 por ciento del significado social de cualquier conversación corresponde a las palabras habladas" (Davis, 2005, p. 42).

Quienes estudian la comunicación no verbal han coincidido en que esta tiene siete áreas: kinésica, características físicas, comportamientos táctiles, paralenguaje, proxémica, artefactos y entorno, pero, es preciso señalar que este trabajo se limitará al análisis de tres de ellas: paralenguaje, kinésica y artefactos.

\subsubsection{Paralenguaje}

Aunque autores como Fernando Poyatos (1994, p. 28) aportan definiciones bien detalladas del paralenguaje y sus componentes, esta categoría de la comunicación no verbal puede resumirse en esta frase: "se refiere a cómo se dice algo y no qué se dice"(Knapp, 1992, p. 24). Paula Requeijo (2010, p. 266) incluye en esta categoría las pausas y los errores al hablar; sin embargo, citando a Trager, tanto Humberto Eco (1986, p. 11) como Knapp (1992, pp. 24-25), coinciden en que los componentes del paralenguaje son:

1. Cualidades vocales: ejemplo, intensidad de los sonidos, resonancia, tiempo. 
Pila Cárdenas, G. La mujer en el poder legislativo de Ecuador: análisis desde la comunicación verbal y no verbal

2. Vocalizaciones, que se dividen en:

2.1. Caracterizantes vocales: risa, llanto, eructo, grito, gemido, voz quebrada.

2.2. Cualificadores vocales: intensidad y tono de voz.

2.3. Segregados vocales: expresiones como hum.

\subsubsection{Kinésica o lenguaje corporal}

Ekman y Friesen (1969), clasificaron los elementos de la kinésica en los siguientes:

1. Emblemas: "son gestos que sustituyen a una palabra o dos; incluso a una frase" (Valbuena, 1997, pp. 521-558).

2. Ilustradores: ilustran lo que el orador está diciendo. "Son actos no verbales íntimamente ligados al discurso hablado" (Knapp, 1992, p. 181). Se dividen en: batutas, ideógrafos, apuntadores, espaciales, kinetógrafos y pictógrafos.

3. Muestras de afecto: "se trata predominantemente de configuraciones faciales que expresan estados afectivos" (Knapp, 1992, p. 21). De acuerdo con Ekman y Friesen (1969, pp. 49-98) los estados afectivos básicos son: alegría, sorpresa, miedo, tristeza, ira y repugnancia o hastío.

4. Reguladores: "indican al hablante que continúe, repita, se extienda en detalles, se apresure, haga más ameno su discurso, conceda al interlocutor su turno de hablar, y así sucesivamente" (Knapp, 1992, p. 21).

5. Adaptadores: "se piensa que se desarrollaron en la niñez como esfuerzos de adaptación para satisfacer necesidades, cumplir acciones, dominar emociones, desarrollar contactos sociales o cumplir con una gran cantidad de otras funciones" (Knapp, 1992, p. 22). Ekman y Friesen distinguieron tres tipos:

5.1 Autoadaptadores: "se refieren a la manipulación del propio cuerpo" (Knapp, 1992, p. 22).

5.2 Heteroadaptadores: "incluyen movimientos para dar a y tomar de otra u otras personas. Son movimientos para atacar o protegerse del ataque" (Valbuena, 1997, pp. 521-558).

5.3 Adaptadores de objeto: "implican la manipulación de objetos y pueden derivar del cumplimiento de alguna tarea instrumental, como fumar, escribir con un lápiz, etc." (Knapp, 1992, p. 23).

\subsubsection{Artefactos}

Comprenden la manipulación de objetos con personas interactuantes que pueden actuar como estímulos no verbales. Estos artefactos comprenden el perfume, la ropa, el lápiz de labios, las gafas, la peluca y otros objetos para el cabello, pestañas postizas, pinturas de ojos y todo el repertorio de postizos y productos de belleza (Knapp, 1992, p. 25).

Para facilitar el desarrollo del trabajo, transcribimos en su totalidad los tres discursos, cuyos textos forman parte de este artículo como anexos. Además, los 
Pila Cárdenas, G. La mujer en el poder legislativo de Ecuador: análisis desde la comunicación verbal y no verbal

videos de estas intervenciones pueden ser vistos desde los enlaces que constan en la bibliografía.

\section{DISCUSIÓN}

\subsection{Gabriela Rivadeneira: discurso de toma de posesión del cargo de presidenta de la Asamblea Nacional del Ecuador}

Con 107 votos afirmativos, de 137 asambleístas, Rivadeneira fue nombrada presidenta de la Asamblea Nacional de Ecuador, por un período de dos años.

\subsubsection{Banda verbal}

\subsubsection{Tipo de discurso}

Este discurso es demostrativo o de exhibición. Como se puede apreciar, existe una recurrencia al presente, la alabanza y la reprobación en los minutos: 00:25, 04:30, 07:33 y 02:07. Un ejemplo del manejo del tiempo es el siguiente: "El día de hoy inauguramos una nueva etapa en la historia del Ecuador" (Rivadeneira, 2013, minuto 00:25).

\subsubsection{Propósito del discurso}

La finalidad que Gabriela Rivadeneira persigue es "inspirar o motivar", puesto que como lo señala Valbuena, en este caso la "emoción"tiene el rol principal y "el mayor secreto de su efectividad es que sean breves". (Valbuena, 1997, pp. 521-558)

\subsubsection{Materiales retóricos}

\subsection{Materiales de credibilidad o ethos}

Se refieren al carácter del orador o las cualidades que le permiten presentarse como una persona fiable, competente y dinámica (Valbuena \& Padilla, 2014, pp. 271302); pero, además, incluyen las características que le permiten atacar a sus contendores o defenderse de los ataques que estos le formulen. Un ejemplo del primer uso es este:

En cuanto a mí, una mujer de veintinueve años, esposa, madre de dos hijos que viene de una ciudad pequeña, pero maravillosa, que ha heredado centenares de luchas y resistencias, Otavalo, perteneciente a la provincia Azul de los Lagos ${ }^{2}$, asumo el reto reconociendo la lucha histórica y perseverante de millones de mujeres y jóvenes a lo largo de los tiempos (Rivadeneira, 2013, minuto 06:36).

\footnotetext{
${ }^{2}$ Imbabura es el nombre real de la provincia.
} 
Pila Cárdenas, G. La mujer en el poder legislativo de Ecuador: análisis desde la comunicación verbal y no verbal

Mientras que ataca a sus contendores políticos cuando señala: "La época en el que el poder legislativo del Ecuador servía a intereses particulares, se ha terminado. Hoy la Asamblea es representativa de cada región y cada territorio del país" (Rivadeneira, 2013, minuto 05:03).

\subsection{Materiales de argumento o logos}

Una de las pocas pruebas inartísticas que se observa, como una constante, en el discurso de Rivadeneira es el voto popular como evidencia de que su designación y la de toda su tienda política, es legítima y tiene respaldo: "El día de hoy inauguramos una nueva etapa en la historia del Ecuador, una etapa que inició el 17 de febrero de 2013, día en el que el pueblo ecuatoriano decidió ratificar en las urnas a la revolución ciudadana como proyecto nacional" (Rivadeneira, 2013, minuto 00:24).

En contraste, este discurso es rico en pruebas artísticas, precisamente debido a su finalidad de "inspirar o motivar". Algunos de los recursos más utilizados por la asambleísta son la enumeración (quince ocasiones), el uso imágenes o alegorías (tres ocasiones), y figuras de contraste (nueve ocasiones).

\subsection{Materiales dramáticos o pathos}

A este tipo de argumentos pertenecen también las pruebas inartísticas. En este espacio nos centraremos en el análisis de la comparación, porque es uno de los recursos dramáticos más importantes utilizados por Gabriela Rivadeneira.

Aunque se observa con claridad solo en dos ocasiones (minuto 06:54 y minuto 08:05), este material es importante porque la oradora logra fijar en la mente del receptor la idea de que la designación de una mujer como presidenta del legislativo es tan importante como la primera mujer que se atrevió a votar o a legislar:

Asumo el reto reconociendo la lucha histórica y perseverante de millones de mujeres y jóvenes a lo largo de los tiempos. Lo asumo con responsabilidad, sencillez y absoluta firmeza, como lo hizo hace ochenta y nueve años Matilde Hidalgo que, con su tenacidad, fue la primera mujer que otorgó un voto popular, y de Nela Martínez que, con su pasión y accionar político, fue la primera legisladora del Ecuador (Rivadeneira, 2013, minuto 06:54).

\subsubsection{Comunicación no verbal}

\subsubsection{Paralenguaje}

Uno de los primeros elementos que se aprecia es el tiempo, que en su caso es bastante equilibrado. En general, la legisladora tiene un registro de voz claro y una correcta articulación de las palabras. En lo referente a los cualificadores vocales, Rivadeneira muestra un tono de voz suave, con ligeras variaciones en la intensidad cuando quiere recalcar la idea de lo nefasto que fue el pasado político del país. 
Pila Cárdenas, G. La mujer en el poder legislativo de Ecuador: análisis desde la comunicación verbal y no verbal

Además, a pesar de haber vivido en Otavalo, una ciudad mayoritariamente indígena, ella no muestra el acento característico de esta zona, que incluye arrastrar la ejecución de ciertos fonemas como / $N$ / (lateral palatal), /j/ (aproximante palatal) 0 /j/ (fricativa palatal sonora), convirtiéndolos en / $/$ / (fricativa postalveolar sorda). Ocurre algo parecido con los fonemas $/ r /$ (vibrante simple alveolar) y /r/ (vibrante múltiple alveolar) que se transforman en /z/ (fricativa retrofleja sonora). Más bien, su acento muestra una clara influencia de la forma de hablar de Quito, la capital del país.

\subsubsection{Kinésica o lenguaje corporal}

La principal batuta que emplea Rivadeneira es mover la cabeza de arriba hacia abajo como señal de que asiente. Utiliza esta batuta 129 ocasiones y, en la mayoría de los casos, su uso coincide con las pausas. Otra de las batutas más recurrentes es mover la cabeza hacia un lado, en un gesto casi infantil de búsqueda de aprobación por parte de la audiencia. Ella realiza este gesto en 36 ocasiones.

También en una ocasión mueve la cabeza hacia atrás, ilustrando justamente esa idea y solo en dos momentos (minuto 1:32 y 05:58) Rivadeneira usa las manos para ilustrar, uno de ellos es cuando señala: "Vino un pueblo rebelde a desordenarlo todo, a cuestionarlo todo y a reinventarlo (batuta) todo" (Rivadeneira, 2013, minuto 01:32). Aquí se observa que utiliza el dedo índice y lo alza verticalmente cuatro veces. Como Morris (1980, p. 61) explica: "actúa como una simbólica clava o palo preparado para caer sobre alguien". En este caso, representa el "poder ciudadano", el poder del "pueblo"listo para caer en sobre quienes están en contra del cambio.

La principal manifestación de afecto es la alegría. Rivadeneira muestra una sonrisa en diferentes niveles, aunque la más común es con los labios y dientes separados, la boca extendida hacia los lados y las mejillas elevadas. Sin embargo, esta emoción no se presenta en estado puro, pues por momentos se muestran rasgos de tristeza o ira. La ira por ejemplo se expresa por un breve instante cuando dice: "Hacía mucho tiempo que nuestra patria no gozaba de paz, de desarrollo, de estabilidad y bienestar como lo tiene ahora"(Rivadeneira, 2013, minuto 00:57).

Finalmente, el autoadaptador más evidente de Gabriela Rivadeneira es humedecer sus labios colocando la lengua entre ellos. Durante su intervención lo hace 21 ocasiones, lo cual denota cierto nerviosismo. La asambleísta solo registra un adaptador de objeto que consiste en acomodar los papeles de su discurso. Ella realiza esta acción solo una vez.

\subsubsection{Artefactos}

Durante el discurso de Rivadeneira hay tres artefactos que destacan por el mensaje que transmiten: la identificación de la oradora con lo indígena. Se trata de la blusa, los pendientes y el peinado. La blusa blanca con pliegues y con el cuello y mangas bordadas a mano (Jaramillo, 1990, p. 138) es una versión occidentalizada de las blusas elaboradas por las mujeres indígenas de la comunidad de Zuleta que se 
Pila Cárdenas, G. La mujer en el poder legislativo de Ecuador: análisis desde la comunicación verbal y no verbal

usan en Otavalo. Es verde porque busca establecer un nexo con el color de su partido político. También usa unos pendientes largos de color dorado, con un espiral al final, símbolo andino que representa una concepción cíclica del tiempo (MirandaLuizaga, 2007, p. 71). Finalmente, su peinado es una trenza que recoge el cabello completamente lo que recuerda la coleta envuelta en una cinta -llamada huangoque es característica de las mujeres indígenas de Otavalo (Jaramillo, 1990, p. 139).

\subsection{Rosana Alvarado: discurso de toma de posesión del cargo de primera vicepresidenta de la Asamblea Nacional del Ecuador}

Alvarado es comunicadora y abogada. Además, ha centrado sus esfuerzos políticos en la lucha por los derechos de las mujeres, impulsando temas polémicos como la despenalización del aborto y la tipificación del femicidio como un delito agravado, lo cual le ha generado críticas de los sectores más conservadores del país.

\subsubsection{Banda verbal}

\subsubsection{Tipo de discurso}

Se trata de un discurso judicial en el cual están presentes dos elementos característicos: el tiempo pasado y la acusación. La asambleísta inicia haciendo una descripción de la identidad de los pueblos que pertenecen al austro de Ecuador, de donde ella es originaria, e inmediatamente acusa en pasado:

Y a este pueblo, amante del preciosismo, a estas mujeres de candongas ${ }^{3}$, a estas mujeres de $i k a t^{4}$ les vino el azote de la colonia, de la esclavitud, de la infamia. Un amo vino después de otro y de otro más. Expulsaron a nuestra gente, expoliaron nuestras riquezas. El oro, la plata, los ahorros, todos migrantes, todos desterrados (Alvarado, 2013, minuto 01:23).

\subsubsection{Propósito del discurso}

El discurso de Alvarado tiene al menos tres finalidades que se manifiestan en distintos momentos. Ella inicia su corta intervención (5 minutos y 58 segundos) con un conjunto de imágenes (minuto 01:58) que tienen el efecto, sobre todo, de conmover, es decir, en esta etapa su discurso tiene la finalidad de "inspirar 0 motivar". Sin embargo, no solo la emotividad gobierna dicha presentación. El objetivo de la legisladora es también "alabar o vituperar", aunque una palabra más justa sería acusar. Finalmente, la asambleísta busca "convencer" a los oyentes acerca de una idea que, como se dijo, ha sido su principal bandera política: la igualdad de género. Alvarado hace mucho énfasis en el gran logro que supone tener un $40 \%$ de mujeres en el Parlamento y que sus tres principales autoridades sean también mujeres.

\footnotetext{
3 Pendientes de plata u oro característicos de la vestimenta de las cholas cuencanas. Ver Astudillo (2012).

${ }^{4}$ Técnica de tejido practicada en Gualaceo, provincia del Azuay. Ver Beltrán (2015).
} 
Pila Cárdenas, G. La mujer en el poder legislativo de Ecuador: análisis desde la comunicación verbal y no verbal

\subsubsection{Materiales retóricos}

\subsection{Materiales de credibilidad o ethos}

Alvarado emplea este tipo de materiales, fundamentalmente, para atacar a sus contendores. De hecho, en todo el discurso apenas se identifican dos afirmaciones de su ethos (minuto 00:09 y 05:13) y ninguna defensa.

En el otro extremo, prácticamente la mitad de su discurso son materiales de credibilidad que usa para atacar a sus contendores políticos y juzgar a los "opresores históricos". Uno de los ejemplos más claros es el siguiente:

Pretendieron dejar eterna la dominación y el sometimiento. Aquí, quienes hoy hablaron de respeto, de democracia, de respeto a los derechos fundamentales. En este salón Plenario, y frente a este mural del maestro, del inalcanzable Guayasamín, votaron por la sumisión, votaron hipotecándole al país, aquí, al Fondo Monetario Internacional, a la banca caníbal. Entregaron territorio nacional a bases extranjeras (Alvarado, 2013, minuto 02:49).

\subsection{Materiales de argumento o logos}

El discurso de Rosana Alvarado es, en gran medida emotivo, por esta razón no se observa mayor utilización de pruebas inartísticas. A pesar de ello, citamos el siguiente párrafo como el mejor ejemplo de la utilización de este tipo de materiales: "El Congreso de la partidocracia del año 94 al 96 les dejó a las mujeres el 4,94\% de participación. El Congreso de la partidocracia de los años 96 al 98 permitió la participación de tan solo un 3\% de mujeres" (Alvarado, 2013, minuto 03:56).

\subsection{Materiales dramáticos o pathos}

Este es quizás uno de los apartados de la retórica más ricos en el discurso de Alvarado. Prácticamente toda la intervención está impregnada de imágenes y alegorías (minutos 00:09, 00:36, 00:53 y 01:58); repetición (minutos 00:53, 01:23, 01:38, 02:54, 03:42, 03:56, 04:39, 04:56 y 05:14), enumeración (minutos 00:09, $00: 37,01: 02,01: 29,01: 49,01: 58,02: 54,05: 14$ y $05: 44:)$ y figuras de contraste (minutos 01:23, 02:54 y 04:56) que constituyen pruebas artísticas creadas por la oradora para mover las pasiones de su audiencia.

Por razones de espacio citamos solo un ejemplo del uso de imágenes y alegorías: "La delicadísima, la des/umbrante filigrana en candongas cantarinas, pavos reales, canastas o el oro esmaltado. Como si el oro, por sí solo, fuera insuficiente" (Alvarado, 2013, minuto 00:36).

\subsubsection{Comunicación no verbal}

\subsubsection{Paralenguaje}

El tiempo de la intervención de Rosana Alvarado es bastante equilibrado y destacan tres de los cualificadores vocales que son: el tono, el volumen y la 
Pila Cárdenas, G. La mujer en el poder legislativo de Ecuador: análisis desde la comunicación verbal y no verbal

extensión. Hemos dividido la intervención en tres momentos para analizar el tono, el volumen y las manifestaciones de afecto:

Tabla 1. Cuadro comparativo del tono, volumen y manifestaciones de afecto.

\begin{tabular}{|l|l|l|l|}
\hline \multicolumn{1}{|c|}{ Fragmento } & \multicolumn{2}{c|}{ PARALNGUAJE } & \multicolumn{1}{c|}{ KINÉSICA } \\
\cline { 2 - 4 } & \multicolumn{1}{|c|}{ Tono } & \multicolumn{1}{c|}{ Volumen } & \multicolumn{1}{c|}{$\begin{array}{c}\text { Manifestaciones de } \\
\text { afecto }\end{array}$} \\
\hline $\begin{array}{l}\text { Minuto 00:05 - 01:22 } \\
\text { Habla de su pueblo, su ciudad y } \\
\text { su cultura. Reivindica sus } \\
\text { derechos de participación política. }\end{array}$ & $\begin{array}{l}\text { Conmoción } \\
\text { y orgullo. }\end{array}$ & $\begin{array}{l}\text { Volumen medio, } \\
\text { cuida que la } \\
\text { intensidad de la } \\
\text { voz no descienda. }\end{array}$ & $\begin{array}{l}\text { Rostro de alegría: sonrisa } \\
\text { de labios y dientes } \\
\text { separados. }\end{array}$ \\
\hline $\begin{array}{l}\text { Minuto 01:22 - 02:41 } \\
\text { Describe parte de la historia de } \\
\text { los pueblos nativos americanos en }\end{array}$ & $\begin{array}{l}\text { Indignación } \\
\text { y tristeza. }\end{array}$ & $\begin{array}{l}\text { Volumen bajo, } \\
\text { voz casi quebrada } \\
\text { como tratando de } \\
\text { fueron invadidos, sino que para } \\
\text { hacerlo se recurrió a prácticas de } \\
\text { extrema crueldad con las culturas } \\
\text { indígenas que allí habitaban. }\end{array}$ & $\begin{array}{l}\text { Rostro de tristeza: mirada y } \\
\text { cejas bajas que se juntan } \\
\text { en los bordes interiores } \\
\text { provocando una arruga } \\
\text { (minuto 01:58). Los labios } \\
\text { descienden formando una } \\
\text { mueca de sonrisa invertida } \\
\text { (minuto 02:01). }\end{array}$ \\
\hline $\begin{array}{l}\text { Minuto 02:48 - final. } \\
\text { Se refiere a los políticos que le } \\
\text { antecedieron y critica las } \\
\text { decisiones que tomaron, pues ella } \\
\text { considera que estas tuvieron un } \\
\text { costo muy alto para el país y los } \\
\text { ecuatorianos. }\end{array}$ & e ira. & $\begin{array}{l}\text { Indignación } \\
\text { entro de ira: cejas juntas } \\
\text { inclinadas hacia abajo, } \\
\text { provocando una arruga y } \\
\text { párpados tensos. Boca } \\
\text { tensa, elevación del labio } \\
\text { superior y ligeras arrugas } \\
\text { en los lados de la nariz. }\end{array}$ \\
\hline
\end{tabular}

Fuente: elaboración propia.

Finalmente está la extensión que:

En el caso de Rosana supone arrastrar los fonemas / $r /$ (vibrante simple alveolar) y /r/ (vibrante múltiple alveolar), que en su forma de hablar se transforman en $/ z /$ (fricativa retrofleja sonora), es decir, en una erre muy marcada. Al igual que el campo tonal melodioso, esta forma particular de arrastrar las palabras es generalizada en los habitantes de esta ciudad, aunque también está presente, con ligeras variaciones, en otras zonas de la sierra centro ecuatoriana (Pila, 2018, p. 339).

La primera vicepresidenta también extiende las palabras que quiere enfatizar, esto es particularmente notorio cuando pronuncia el fragmento de Boletín y elegía de las mitas, un poema del escritor cuencano César Dávila Andrade (Alvarado, 2013, minuto 01:58).

\subsubsection{Kinésica o lenguaje corporal}

En la intervención de Alvarado se observan fundamentalmente dos tipos de ilustradores: batutas y apuntadores. Son dos las batutas de Alvarado, con la cabeza 
Pila Cárdenas, G. La mujer en el poder legislativo de Ecuador: análisis desde la comunicación verbal y no verbal

y rostro: levantar cejas (47 veces) y movimiento de la cabeza de arriba hacia abajo (43 ocasiones).

También hace 35 repeticiones de la batuta dedo índice levantado, con movimiento de mano de arriba hacia abajo. Esta batuta, tiene dos variaciones que son palma de lado, con movimiento de mano de arriba hacia abajo (8 repeticiones); y palma arriba, con movimiento de mano de arriba hacia abajo (una vez). De manera marginal, también aparecen las siguientes batutas: dedo índice levantado con movimiento circular (una vez), palma de lado con movimiento de lado a lado (una vez) y asimiento de vacío (una vez).

La asambleísta cuencana también emplea tres apuntadores durante su intervención: índice extendido con movimiento hacia abajo (8 veces), pulgar levantado con movimiento de la mano hacia atrás (7 veces) e índice levantado que apunta hacia arriba (3 veces). Uno de los reguladores que se aprecia en este discurso es el de los aplausos. Este regulador aparece por siete ocasiones en los minutos: 02:41, 03:18, 03:46, 04:27, 05:10, 05:31 y 05:55. Otro regulador aparece al final de la intervención, cuando la legisladora dice: "iViva la patria!" para concluir. La audiencia, grita "iViva!", con esta respuesta los receptores, una vez más, muestran su activo interés y respaldo al discurso de Alvarado.

La legisladora recurre a los adaptadores en 13 ocasiones, 9 de las cuales son autoadaptadores y 4 , adaptadores de objeto. Los autoadaptadores que se observan son: arreglarse el cabello con un movimiento de cabeza (cuatro veces), colocarse el cabello detrás de la oreja con la mano (una vez) y lamerse los labios (cuatro veces). Observamos solo un adaptador de objeto que consiste en acomodar las hojas del discurso sobre el atril, lo cual ocurre cuatro veces.

\subsubsection{Artefactos}

En esta presentación, Alvarado aparece con un vestido violeta de seda o algún material con textura similar. Se trata de un corte bastante conservador, pero elegante, que tapa su cuerpo hasta el cuello. Sin embargo, lo que realmente resalta en este apartado es el abultado collar de perlas que usa, que a simple vista parece un artefacto más, pero que en realidad emula una joya indígena conocida como gualca ${ }^{5}$. Aunque las cholas cuencanas -mujeres indígenas de la ciudad de origen de Alvarado- no suelen usar este tipo de joya, es importante señalar que la asambleísta quiso establecer un nexo entre su condición de mestiza (el vestido) y su orgullo de lo indígena.

\subsection{Marcela Aguiñaga: discurso de toma de posesión del cargo de segunda vicepresidenta de la Asamblea Nacional del Ecuador}

Marcela Aguiñaga es una abogada proveniente de la ciudad de Guayaquil, la más poblada del país y referente de desarrollo en la región costa. Antes de ser asambleísta,

\footnotetext{
${ }^{5}$ Collar compuesto por varias hileras de cuentas de vidrio, plástico o coral usado tradicionalmente por
} las mujeres indígenas de la sierra ecuatoriana. 
Pila Cárdenas, G. La mujer en el poder legislativo de Ecuador: análisis desde la comunicación verbal y no verbal

Aguiñaga se desempeñó como Ministra de Ambiente en el período comprendido entre noviembre de 2007 y noviembre de 2012, siendo la secretaria de Estado que más tiempo estuvo en esa cartera en el Gobierno del presidente Rafael Correa.

\subsubsection{Banda verbal}

\subsubsection{Tipo de discurso}

Se trata de un discurso deliberativo. Aunque Aguiñaga no usa directamente el futuro como tiempo verbal, continuamente hace llamados, a la ciudadanía a y sus compañeros legisladores, que solo se pueden concretar en el futuro.

\subsubsection{Propósito del discurso}

Este discurso tiene fundamentalmente la finalidad de "convencer". Como se observa, en este caso el recurso principal es el "razonamiento", mientras que la emoción -a diferencia de lo que ocurre con las intervenciones de Rivadeneira y Alvarado- tiene un rol marginal (Valbuena de la Fuente, 1997, pp. 521-558).

\subsubsection{Materiales retóricos}

\subsection{Materiales de credibilidad o ethos}

El único momento en que ella habla de sus materiales de credibilidad en primera persona del singular es el siguiente: "Recibo este encargo de ustedes, colegas asambleístas, agradecida, pero con la firmeza y la convicción necesarias para afrontar el reto con transparencia, con firmeza y con honestidad" (Aguiñaga, 2013, minuto 04:00).

Por otra parte, también en solitario, el material de credibilidad que se identificó como un ataque a sus contendores políticos es el siguiente: "Hoy un asambleísta, que ahora dice defender a la naturaleza, visitaba mi despacho cuando era ministra de Ambiente, pidiendo por los mineros ilegales. Eso es lo que está representado, ése es el pasado que debe quedar atrás"(Aguiñaga, 2013, minuto 03:19).

\subsection{Materiales de argumento o logos}

Encontramos tres materiales de argumento o logos (en los minutos 00:53, 02:06 y 03:19) que corresponden a lo que Aristóteles denomina pruebas inartísticas. Citamos el siguiente ejemplo: "Hay urgencias que debemos enfrentar y estamos, quizás, ante la única oportunidad de ejercer una gestión legislativa sin bloqueos mezquinos como en el pasado" (Aguiñaga, 2013, 02:06). Citamos este fragmento porque en ese período, el Movimiento Alianza PAIS obtuvo una sólida mayoría compuesta por 100 de 137 legisladores.

\subsection{Materiales dramáticos o pathos}

El discurso de Aguiñaga es fundamentalmente racional, por lo que no se observa mayor uso de materiales dramáticos. El principal recurso que ella emplea es la enumeración (cuatro veces). De manera marginal, encontramos la repetición (dos 
Pila Cárdenas, G. La mujer en el poder legislativo de Ecuador: análisis desde la comunicación verbal y no verbal

veces) y el uso de imágenes y alegorías (una vez). Citamos el siguiente ejemplo porque es el que mejor recoge la idea del pathos: "Hoy se cristaliza uno de los anhelos largamente esperados por un país que en los últimos seis años se ha caracterizado por derrumbar mitos y promover la inclusión y la equidad, dos conceptos que hace antaño fueron despreciados por la clase política" (Aguiñaga, 2013, minuto 00:30).

\subsubsection{Comunicación no verbal}

\subsubsection{Paralenguaje}

En cuanto al tiempo, no hay diferencia entre Marcela Aguiñaga y sus compañeras legisladoras, puesto que las tres muestran un tiempo equilibrado, adecuado para la situación, el escenario y el tipo de audiencia que tienen. En relación con los cualificadores vocales, el tono de la representante de la provincia del Guayas, que es casi el mismo durante toda la intervención, es fundamentalmente profesional, políticamente correcto y poco confrontativo. Relacionado con lo anterior, encontramos que Aguiñaga muestra un volumen medio, casi sin variaciones a lo largo de su intervención.

La única variación que encontramos, tanto en el tono como en el volumen de Aguiñaga, se produce cuando habla de la visita que recibió, como ministra de Ambiente, por parte de un legislador presente en la sala, para abogar a favor de los mineros ilegales (minuto 03:19) que ya fue citado antes. En este fragmento del discurso, el tono de Aguiñaga cambia a la indignación y el reproche; y para ratificar este sentimiento, el volumen de su voz se eleva un poco.

En lo referente a la extensión, debido a su acento característico de la costa ecuatoriana (en general, similar en las zonas tropicales latinoamericanas de habla hispana), la oradora corta las palabras, sobre todo aquellas que tienen el fonema /s/ al final de una sílaba como, por ejemplo: somos, características, entre otras. Si se pone atención, lo que ocurre en realidad es que ella reemplaza el fonema $/ \mathrm{s} /$ (fricativa alveolar sorda) por el fonema / $\mathrm{x} /$ (fricativa velar sorda), con lo cual las palabras anteriores suenan: / 'somox/, /karakte' rixtikax/. Aunque, para un oído poco acostumbrado a esta forma de hablar, parecería que el fonema /s/ directamente se omite.

\subsubsection{Kinésica o lenguaje corporal}

En términos generales, Marcela Aguiñaga emplea muy poco las manos, por esta razón, la mayor parte de los gestos correspondientes a la sección de ilustradores se producen con la cabeza. En esta intervención la asambleísta exhibe fundamentalmente tres tipos de ilustradores: batutas, apuntadores e ideógrafos.

Las batutas están presentes de dos maneras: movimiento de cabeza de arriba hacia abajo (61 repeticiones) y dedo índice levantado con movimiento de mano de arriba hacia abajo (6 repeticiones). Debido a que la segunda batuta es una señal de 
Pila Cárdenas, G. La mujer en el poder legislativo de Ecuador: análisis desde la comunicación verbal y no verbal

codena o reproche, la asambleísta la usa solo cuando se refiere al único tema claramente negativo de su discurso: la visita del legislador que abogaba por la minería ilegal.

Aguiñaga usa apuntadores en tres momentos, el primero es cuando se refiere a sus compañeras Gabriela Rivadeneira y Rosana Alvarado, quienes se encuentran ya en el podio principal. El segundo es cuando se refiere al asambleísta (presente en la sala) que la visitó para abogar por la minería ilegal. El tercer momento ocurre al final, cuando la oradora se despide de la audiencia. Aguiñaga pronuncia la frase: "iGracias pueblo ecuatoriano!" y señala con su mano hacia las barras altas, donde está la gente, con el apuntador de mano levantada con palma hacia atrás, una vez.

También se sirve de los ideógrafos en dos ocasiones, en los minutos 03:16 y 03:29. Ambos marcan la idea de tiempo: "Eso es lo que está representado, ese es el pasado que debe quedar atrás (ideógrafo)" (Aguiñaga, 2013, 03:29). En ambos casos, el ideógrafo utilizado consiste en levantar el dedo índice apuntando hacia atrás.

Por otra parte, identificamos tres muestras de afecto: alegría, ira y sorpresa. Como sabemos, la risa y la sonrisa son los principales gestos de la alegría. Creemos que esta es una de las manifestaciones de afecto presentes en el discurso de Aguiñaga, pues antes de iniciar su intervención, muestra una gran sonrisa caracterizada por una mueca de labios separados y dientes juntos, pero visibles, lo cual eleva las mejillas y arruga ligeramente los párpados, que crean el efecto de empequeñecer los ojos.

A pesar de la intensidad de este primer gesto, luego solo se aprecian sonrisas tímidas pero constantes a lo largo de la presentación. Este tipo de sonrisas aparecen en los segundos 00:16, 00:19 y 00:47; y en los minutos 01:02, 01:20, 01:29, 02:44, 03:24 y 03:29. En general, se observa que los momentos de alegría de Aguiñaga están relacionados con su designación como autoridad del legislativo, con los logros políticos de la mujer y con los cambios positivos que, desde su punto de vista, se han producido con la "revolución ciudadana".

En contraste, la ira aparece fundamentalmente en la parte superior del rostro, especialmente las cejas, que se acercan e inclinan hacia abajo provocando una arruga entre ellas. Los párpados y boca tensa acompañan esta manifestación de afecto que -al igual que ocurrió con la alegría- en el caso de Aguiñaga, no se muestra de manera intensa. Esta manifestación de afecto aparece asociada a los componentes verbales que representan una idea negativa para ella como el siguiente: "Hay urgencias que debemos enfrentar y estamos, quizás (ceja de ira), ante la única oportunidad (ceja de ira) de ejercer una gestión legislativa sin bloqueos mezquinos como en el pasado" (Aguiñaga, 2013, minuto 02:05).

La sorpresa aparece, en cambio, cuando narra la visita que le hizo un asambleísta presente en el salón, cuando era ministra de Ambiente, para abogar por la minería ilegal. Esta muestra de afecto se expresa en lo que se denomina ceja de sorpresa, 
Pila Cárdenas, G. La mujer en el poder legislativo de Ecuador: análisis desde la comunicación verbal y no verbal

que consiste elevar esta parte del rostro más de lo habitual, lo cual produce largas arrugas horizontales en la frente, como en efecto se observa en el rostro de la oradora en los minutos 03:15 y 03:19.

Los aplausos son el único regulador que se aprecia en la presentación de la legisladora guayaquileña, estos aparecen como una respuesta de los receptores tan solo en dos ocasiones, en los minutos 03:19 y 03:30, precisamente cuando la oradora improvisa, lo cual muestra que es el momento mejor recibido por su audiencia.

El lenguaje corporal de la legisladora muestra tranquilidad y ausencia de nerviosismo la mayor parte de la intervención. El único autoadaptador que observamos es acomodarse el cabello con movimiento de cabeza, 15 veces. Aunque 15 veces parecen muchas, si se observa el video con detenimiento, se advierte que este gesto está más relacionado con la incomodidad que le produce su peinado (pues su cabello cae varias veces hasta sus ojos) que con un estado de nerviosismo. En la intervención de la legisladora se aprecian tan solo dos adaptadores de objeto: tocar el micrófono (una vez) y acomodar las hojas (dos veces).

\subsubsection{Artefactos}

Aguiñaga, en contraste con la vestimenta escogida por sus compañeras, aparece con un atuendo completamente occidental, compuesto por un traje formal de chaqueta y falda de color gris oscuro, una blusa azul y un collar largo que corta la sencillez de la blusa. En este conjunto de prendas no existen elementos que se puedan asociar con una cultura indígena (como en el caso de Rivadeneira y Alvarado) o tradicional de la costa ecuatoriana. Al contrario, parece que la asambleísta busca mostrar su verdadera personalidad e incluso marca distancia del color característico de su partido político, el verde.

\section{CONCLUSIONES}

Lo más destacable en Gabriela Rivadeneira es la construcción retórica de su discurso, pues está llena de imágenes y alegorías que logran conmover a los receptores a lo largo de toda la intervención, a pesar de ello, tiene un lenguaje corporal monótono. Se advierte que hubo ensayo previo, sin embargo, muestra su nerviosismo mediante el uso repetitivo del autoadaptador que consiste en humedecer sus labios colocando la lengua entre ellos. De las tres mujeres en el poder legislativo, ella es la que mayor significado transmite a través de los artefactos.

Rosana Alvarado es la oradora que logra el mejor resultado si se analiza el lenguaje verbal y la comunicación no verbal en conjunto. Su discurso es fundamentalmente emotivo, ya que se sirve de materiales dramáticos muy conmovedores a lo largo de toda su intervención. En general, su lenguaje corporal demuestra dominio de la situación y refleja su experiencia como oradora. Sus gestos transmiten naturalidad al receptor y su verdadero compromiso con las palabras que pronuncia. 
Pila Cárdenas, G. La mujer en el poder legislativo de Ecuador: análisis desde la comunicación verbal y no verbal

Marcela Aguiñaga se diferencia de sus compañeras mostrando un estilo profesional y pulido en su forma de comunicar. Su discurso está marcado por elementos racionales más que emotivos. Constantemente, la legisladora deja ver que su origen político no es el de la elección popular sino la gestión y el trabajo técnico. De las tres oradoras, es la que menor cantidad de materiales de credibilidad utiliza, tanto para la defensa como para el ataque, lo cual marca distancia entre ella y el estilo de alabar y vituperar de sus compañeras.

Las tres legisladoras buscan proyectar los rasgos identitarios de género y de la cultura que representan. A pesar de que las tres parecen tener estilos distintos de comunicar, en realidad forman un conjunto que se complementa. Juntas representan tres de las regiones más importantes del país (sierra norte y centro, sierra sur y costa), lo cual las vuelve un elemento articulador en medio de las distancias físicas y culturales.

\section{REFERENCIAS}

Agencia EFE. (2013, octubre 11). Gabriela Rivadeneira, la encarnación de la revolución ciudadana. El Tiempo. Recuperado de http://bit.ly/2LSEfPq

Aguiñaga, M. (2013). Discurso de toma de posesión como segunda vicepresidenta de la Asamblea Nacional del Ecuador. Ecuador: Televisión Legislativa. Recuperado de http://bit.ly/20kQgi5

Alvarado, R. (2013). Discurso de toma de posesión como primera vicepresidenta de la Asamblea Nacional del Ecuador. Ecuador: Televisión Legislativa. Recuperado de http://bit.ly/2v9VZP9

Aristóteles. (1990). Retórica. Madrid: Editorial Gredos.

Asamblea Constituyente del Ecuador. Constitución de la República del Ecuador (2008). Ecuador: Registro Oficial No. 449 del 20 de octubre de 2008. Recuperado de http://bit.ly/2LVz1Tf

Asamblea Nacional del Ecuador. Ley Orgánica Electoral y de Organizaciones Políticas de la República del Ecuador - Código de la Democracia (2009). Ecuador: Registro Oficial No. 578 del 27 de abril de 2009. Recuperado de http://bit.ly/2v9dUpf

Astudillo, G. (2012). La candonga ya no es una joya exclusiva de la chola cuencana. El Comercio. Recuperado de http://bit.ly/2M52sIP

Bejarano, M. (2013). El uso del lenguaje no sexista como herramienta para construir un mundo más igualitario. Vivat Academia, 124, 79-89. Recuperado de http://www.vivatacademia.net/index.php/vivat/article/view/191

Beltrán, J. (2015). El Ikat es el nuevo patrimonio inmaterial del Ecuador. El Comercio. Recuperado de http://bit.ly/2uZqg3Z 
Pila Cárdenas, G. La mujer en el poder legislativo de Ecuador: análisis desde la comunicación verbal y no verbal

Berlanga, I., García, F., \& Victoria, J. (2013). Ethos, pathos y logos en Facebook. El usuario de redes: nuevo «rétor» del siglo XXI. Comunicar, 41, 127-135. https://doi.org/10.3916/C41-2013-12

Cisneros-Palacios, F. (2013, junio). Paridad y representación en la nueva Asamblea Nacional. Opinión Electoral. Gaceta de análisis político electoral, pp. 4-5. Recuperado de http://bit.ly/2uQ2SWs

Consejo Nacional Electoral. (2013). Resultados Electorales. Elecciones Generales 2013. Quito. Recuperado de http://bit.ly/2uUSOqe

D'Elia, N. (2013). La mujer en la política: ¿igualdad o diferencia? Una invitación a la reflexión. Revista de la SEECI, 32, 31-40. https://doi.org/10.15198/seeci.2013.32.31-40

Davis, F. (2005). La Comunicación no verbal (8ª reimp.). Madrid: Alianza.

Del-Valle, M. (2008). Aproximación a la indumentaria como símbolo cultural: un recorrido histórico. Revista de la SEECI, 16, 74-97. Recuperado de http://www.seeci.net/revista/index.php/seeci/article/view/177

Eco, H. (1986). La estructura ausente. Barcelona: Editorial Lumen.

Ekman, P., \& Friesen, W. (1969). The repertoire of nonverbal behavior: Categories, origins, usage, and coding. Journal of the International Association for Semiotic Studies/Revue De l'Association Internationale, 1, 49-98.

Espizua, I., \& Padilla, G. (2017). La imagen y el estilo de la mujer política española como elementos básicos de su comunicación. Revista de la SEECI, 42, 62-84. https://doi.org/10.15198/seeci.2017.42.62-84

Fast, J. (1999). El lenguaje del cuerpo (15ª ed.). Barcelona: Kairós.

García, A., Lagos, S., \& Román, M. (2018). Constitución española en la columna "Escenas políticas" de Campmany. Vivat Academia, 144, 51-67. https://doi.org/10.15178/va.2018.144.51-67

Jácome, J. (2013, mayo 14). Tres mujeres dirigen ya la Asamblea Nacional. Ecuador en vivo. Recuperado de http://bit.ly/2LqEQf8

Jaramillo, H. (1990). La indumentaria indígena de Otavalo. Sarance, 14, 127-144. Recuperado de http://bit.ly/2mMhDW1

Knapp, M. (1992). La comunicación no verbal. El cuerpo y el entorno. Barcelona: Paidós. 
Pila Cárdenas, G. La mujer en el poder legislativo de Ecuador: análisis desde la comunicación verbal y no verbal

Miranda-Luizaga, J. (2007). Categorías filosóficas del pensamiento andino. En M. Acconero (Ed.), El arte y el diseño en la cosmovisión y pensamiento americano (pp. 71-74). Códoba: Editorial Brujas. Recuperado de http://bit.ly/2LqlUwY

Morris, D. (1980). El hombre al desnudo: un estudio objetivo del comportamiento humano. Barcelona: Ediciones Nauta.

Padilla, G. (2015). La espectacularización del debate electoral: estudio del caso en Estados Unidos. Vivat Academia, 132, 162-181. Recuperado de http://www.vivatacademia.net/index.php/vivat/article/view/587/130

Pila, G. (2018). Componentes verbales y no verbales en tres tipos de discursos: análisis de casos. En R. Vega-Baeza \& P. Requeijo-Rey (Eds.), La Universidad y nuevos horizontes del conocimiento (pp. 333-347). Madrid: Editorial Tecnos.

Piñeiro, M. (2003). Representaciones femeninas en la publicidad. Una propuesta de clasificación. Revista de la SEECI, 10, 1-16. https://doi.org/10.15198/seeci.2003.10.1-16

Poyatos, F. (1994). La comunicación no verbal II. Paralenguaje, kinésica e interacción (Primera Ed). Madrid: Ediciones Itsmo.

Requeijo, P. (2010). El estilo de comunicar de Barack Obama. CIC Cuadernos de Información y Comunicación, 15, 263-285.

Rivadeneira, G. (2013). Discurso de toma de posesión como presidenta de la Asamblea Nacional del Ecuador. Ecuador: Televisión Legislativa. Recuperado de http://bit.ly/2Ad3yu3

Rodríguez, J. (2018). Estudio en cognición social: el vestuario y su vinculación como elemento de análisis en la comunicación no verbal. Vivat Academia, 143, 85-110. https://doi.org/10.15178/va.2018.143.85-110

Valbuena de la Fuente, F. (1997). Teoría general de la información. Madrid: Noesis.

Valbuena, F. (1997). Comunicación Institucional (II): Presentaciones y Debates. En A. El-Mir \& F. Valbuena (Eds.), Manual de Periodismo (pp. 521-558). Las Palmas de Gran Canaria: Prensa Ibérica.

Valbuena, F., \& Padilla, G. (2014). Los debates políticos televisados. En J. Herrero \& R. Max (Eds.), Comunicación en campaña. Dirección de campañas electorales y marketing político (pp. 271-302). Madrid: Pearson. 
Pila Cárdenas, G. La mujer en el poder legislativo de Ecuador: análisis desde la comunicación verbal y no verbal

\section{AUTORA:}

\section{Geoconda Pila Cárdenas}

Cursa el doctorado en Comunicación Audiovisual, Publicidad y Relaciones Públicas en la Universidad Complutense de Madrid. Máster universitario en Comunicación Política y Empresarial por Universidad Camilo José Cela de Madrid. Licenciada en Comunicación Social por la Universidad Central del Ecuador y mejor egresada de su promoción. Ha sido asesora de comunicación política en las Comisiones de Justicia y Estructura del Estado; y de la Biodiversidad y los Recursos Naturales en la Asamblea Nacional del Ecuador, en donde ha trabajado directamente con sus presidentes.

gpila@ucm.es

ORCID: https://orcid.org/0000-0002-2624-4543

Google Scholar: http://bit.ly/2UDxHsN

ResearchGate: https://www.researchgate.net/profile/Geoconda Pila Cardenas

ResearcherID: http://www.researcherid.com/rid/L-7355-2018 